\title{
MATHEMATICAL MODELLING OF THE BRIDGES STRUCTURAL MONITORING II
}

\author{
G.M.T. Rădulescu ${ }^{\text {a, }}{ }^{*}$, A.T.G. Rădulescu ${ }^{\text {a }}$, M.V.G. Rădulescu ${ }^{\text {a }}$, Sanda Naş ${ }^{\text {a }}$ \\ ${ }^{a}$ Technical University of Cluj Napoca, Faculty of Civil Engineering, Department of Terrestrial Measurement and Cadastre, \\ 25 G. Baritiu St., 400027 Cluj-Napoca, Romania, e-mail: * gmtradulescu@yahoo.com, adrian_r1982@yahoo.com, \\ mihairadulescu77@yahoo.com, sanda.nas@mtc.utcluj.ro
}

Received: 11.03.2015 / Accepted: 19.03.2015 / Revised: 09.04.2015 / Available online: 31.05.2015

DOI: 10.1515/jaes-2015-0012

KEY WORDS: Incheon Grand Bridge, Structural Health Monitoring, Mathematical Model, Sensors, Steel Structural Element

\begin{abstract}
:
We have seen in the previous paper that in the case of resistance elements made of steel, at least in this case study, the structure's response to strains, in this case sunshine, is uncertain, may or may not be linear. The analysis continues for the four characteristic months of 2013, respectively the second month (February), the fifth (May), the eighth (August) and the event (November), covering the four seasons and approximately the entire range of temperatures to which the resistance elements of the bridge are subject to along a calendar year - case study Incheon Grand Bridge, Seoul, South Korea. The number of data pairs recorded, as we have noted, every 15 minutes, is initially 11,616, being difficult to process. Some software (e.g. Table Curve 2D) can work with a maximum of 3000 data pairs. In what follows we will examine the behaviour of a reinforced concrete element of the North Bridge Gap front line and we will build a mathematical model of its behaviour to sunshine, from the input data, one recording every hours, thus reducing the number of measurements to 2904 . The aim is to obtain a mathematical model with a correlation coefficient above 0.9 , which is also verified and validated. This model will allow us to calculate the expected position of the sensor mounted on the resistance element for a certain temperature, the degree of confidence of the result, the interval of residual values. Because the history of the evolution of temperatures for each moment analyzed is different it produces different results, but ones that fit the specified regressive mathematical model.
\end{abstract}

\section{INTRODUCTION}

1.1 General considerations of the mathematical regression method

The Correlation method is that through which we determine possible associations between the values of two continuous statistical variables on the same subject. The verification index of this correlation is the Correlation coefficient. It can be calculated for any set of data but in order to have statistical significance, two conditions must be met:

1. The two sets of data must refer to one and the same subject,

\footnotetext{
* Corresponding author.
}

2. At least one variable must have a normal distribution, the ideal being that both are normally distributed.

If the data does not satisfy this condition they shall be transformed for normalization or non-parametric correlation coefficients shall be considered. If both variables are approximately Gaussian, besides the Correlation coefficient, we can obtain a Confidence interval corresponding to it.

We consider two statistical series $\left\{x_{i}\right\}_{1 \leq i \leq n}$ and $\left\{y_{i}\right\}_{1 \leq i \leq n}$ corresponding to the statistical variables $X$ and $Y$, generated by a group of information taken, directly connected to a single topic. The Correlation coefficient $r$ 
of the two variables, also called Pearson, $\boldsymbol{s} \boldsymbol{r}$ means the real number $r$, between -1 and 1, defined by the relationship, used by different software (IBM SPSS, Table Curve, DataFit 9.1., Matlab, LogFit, etc.):

$$
r=\frac{\sum_{i=1}^{n}\left(x_{i}-\bar{x}\right) \cdot\left(y_{i}-\bar{y}\right)}{\sqrt{\sum_{i=1}^{n}\left(x_{i}-\bar{x}\right)^{2} \cdot \sum_{i=1}^{n}\left(y_{i}-\bar{y}\right)^{2}}}
$$

Theorem: The Correlation coefficient $\boldsymbol{r}$ of two random variables $X$ and $Y$ takes values in the range $[-1,+1]$, it is void if the variables are independent and equal to -1 or +1 if and only if variables $X$ and $Y$ verifies the equation:

$$
a X+b Y=c \Leftrightarrow Y=A X+B, a, b, c, A, B \in R
$$

The correlation coefficient $r$ has values between -1 and 1, passing through a value of 0 to indicate a non-linear association between these two variables (practically linear independence):

- value of $r$ close to -1 indicates a strong negative correlation, i.e. a variable's tendency to decrease strongly when the other variable increases,

- value of $r$ close to 1 indicates a strong positive correlation, i.e. a variable's tendency to increase strongly when the other variable increases.

In this paper we encounter both cases. In conclusion, the correlation coefficient is a measure of the "arithmetic" linear relationship between the two variables that can sometimes be random, without real relevance. But if the relationship between the two variables is not random, then there may be three possible explanations:

- The variable $X$ influences [(causes) variable $Y$;

- Variable $Y$ influences [(causes) variable $X$;

- Both variables $X$ and $Y$ are influenced by the same background phenomenon, different from this.

The linear relationship between the two variables is described by linear equations, the so-called regression equation. The geometric correspondent of the regression equation is the regression line.

For numerical variables, the dependent variable is distributed on the ordinate axis and the independent one on the $x$-axis.
It is said that the line $y=a_{0}+b_{0} x$ optimally linearizes experimental data $\left(x_{i}, y_{i}\right), 0 \leq i \leq n$ and is called the regression line of $y$ with respect to $x$.

The regression line is that ideal line passing through the point cloud made of data pairs of the two variables, which minimizes the distance between the data and it (minimizing the sum of squared residual distances). Particularly, the method is to calculate vertical distances between the real points observed, corresponding to the pair of statistical series and imaginary points on a given regression line, passing through the cloud of points generated by the points of the data pair. These distances are called waste.

Finally we obtain the regression equation:

$$
Y=a+b X
$$

where: $a$ is called interceptor and $b$ is called regression coefficient - slope of the regression line. The standard mode of simultaneous verification of all three work hypotheses is the statistical analysis of residues. Thus, it can be shown that if all three hypotheses are tested simultaneously, then the residue is normally distributed by the mean zero. Even if the correlation coefficient value is not enlightening, the significance level $p$ can be calculated using Dell Software Statistics. The regression method can be extended from pairs of two variables to several variables using the multiple linear regression method, where we have one dependent variable and several predictive variables. The author will use this method in subsequent studies. The author has used statistical processing of data pairs from the Structural Monitoring made on Incheon Bridge and the $351.5 \mathrm{~m}$ smoke chimney on the industrial platform of Baia Mare, made with the following software DataFit 9.1., Dell Software Statistics, Table Curve 2D, Table Curve 3D, Autocad, CADian, SimFit and IBM SPSS 21. Statistics Standard Edition.

1.2 Integration of the sensor mounted on the monitored element Bridge Gap from North line in the monitoring system of Incheon Grand Bridge

As stated in the previous paper, the structural monitoring of the bridge is done using Ultrasonic sensors UPK2500 and UPK500 mounted on six structural elements of the bridge, four made of metal and two of reinforced concrete. Figure 1 shows the position of each sensor on the structure and its nature. It is noted that UPK500 sensors are 
mounted on steel elements and UPK2500 on the reinforced concrete elements, the case study Bridge Gap from North line falling into this category.

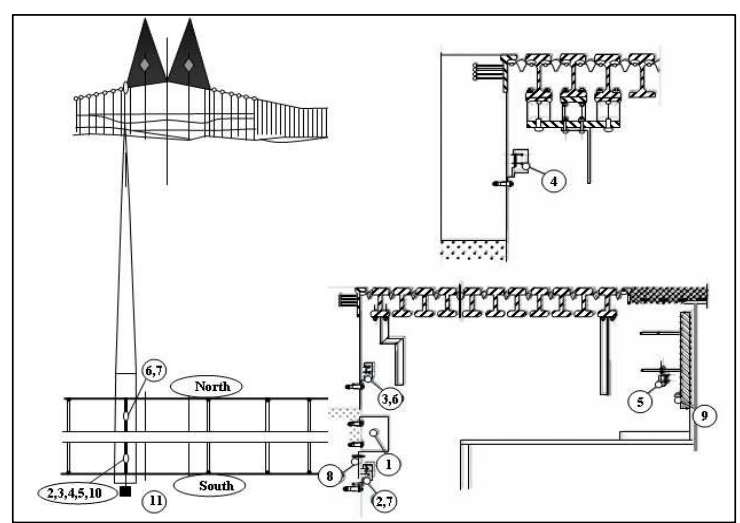

1. ROBOCONTROL box with integrated temperature sensor(Soth)

2. Ultras. sensor UPK2500 for measurem. of Bridge Gap(Soth)

3. Ultras. sensor UPK500 for measurem. of Gap at first lamella (Soth)

4. Ultras. sensor UPK500 for measurem. of Gap at second lam.(Soth)

5. Ultras. sensor UPK500 for measurem. Gap at 24(last) lamella(Soth)

6. Ultras. sensor UPK500 for measurem. of Gap at first lam.(North)

7. Ultras. sensor UPK 2500 for measurem. of Bridge Gap(North)

8. Temperature sensor concrete structure(Soth)

9. Temperature sensor steel structure(Soth)

10. Weather sensor

11. Solar panel

Figure 1. The sensor location on the backbone of the bridge, RoboControl box, ultrasonic and temperature sensors mounted on the structure (Source: VCE)

\section{PROCESSING DATA FOR BRIDGE GAP FROM NORTH LINE, DURING THE MONITORING PERIOD FEBRUARY, MAY, AUGUST AND NOVEMBER OF 2013}

2.1. The original selection of data processed

The authors interpreted the data for the following months of 2013: February - winter month, May - spring month, August - summer month and November - autumn month, with temperatures between the limits specified in Table 1.
As a general way of building mathematical models that define behaviour to uneven sunshine of elements of the bridge we reduced by half the number of records, sequentially. Further, in order to be processed, the data were selected hourly reducing the amount of data from $\sim 11600 \times 9$ to $\sim 2900 \times 9$, then two hours, respectively $\sim 1450 \times 9$ possible correlations and finally $\sim 725 \times 9$ with a recording interval of 4 hours. Based on initial data we constructed the synthetic diagrams shown below (Figure 2 ), which show the general correlation between changes in atmospheric temperature and movement of bridge blades, reported by the position of sensors mounted on it, for the four months mentioned earlier. For this case study, the element Bridge Gap from North line, we reduced the number of recordings from 11,606 , namely one recording every 15 minutes, to one recording every hour.

\begin{tabular}{|c|c|c|c|c|}
\hline \multirow[b]{2}{*}{ M. } & \multicolumn{2}{|c|}{ Temperature Min. } & \multicolumn{2}{|c|}{ Temperature Max. } \\
\hline & $\mathrm{T}^{\circ} \mathrm{C}$ & $\begin{array}{l}\text { Moment of } \\
\text { recording }\end{array}$ & $\mathrm{T}^{\circ} \mathrm{C}$ & $\begin{array}{l}\text { Moment of } \\
\text { recording }\end{array}$ \\
\hline II & $-11,60$ & $\begin{array}{l}07.02 ; \\
23: 13\end{array}$ & 11,80 & $28.02 ; 11: 19$ \\
\hline $\mathrm{V}$ & 9,01 & $\begin{array}{l}05.05 \\
18: 19\end{array}$ & 28,06 & $05.26 ; 6: 22$ \\
\hline $\begin{array}{l}\text { VI } \\
\text { II }\end{array}$ & 22,15 & $\begin{array}{l}22.08 \\
23: 36\end{array}$ & 33,63 & $22.08 ; 9: 21$ \\
\hline XI & $-3,23$ & $\begin{array}{l}28.11 ; \\
2: 06\end{array}$ & 18,63 & $01.11 ; 11: 06$ \\
\hline
\end{tabular}

Table 1. Extreme temperatures and recording date for the four months of monitoring (Source: Authors/VCE)

2.2. Processing of initial data, time interval for recording - one hour

Entering the data in the program we obtain 83 equations which define the relationship between the two sets of data, $x$, representing the temperature of the steel and $y=f(x)$ the position of the sensor, relative to a predetermined fixed origin. In general, as a mathematical model we chose the first equation, Rank 1 or the closest one to an operable model. In this case, the first equation is:

1. $y^{2}=a+b x+c x^{2}+d x^{3}+e x^{4}$

Correlation coefficient $\mathrm{r}^{2}=0.9809$ showing a highly significant correlation between the input data into the program. The following equations are:

2. $y=a+b x+c x^{2}+d x^{3}+e x^{4}$

Correlation coefficient $\mathrm{r}^{2}=0.9808$

3. $y^{0,5}=a+b x+c x^{2}+d x^{3}+$

Correlation coefficient $r^{2}=0.9808$ 
4. $y=a+b x+c x^{2}+d x^{3}+e e^{-x}$

Correlation coefficient $\mathrm{r}^{2}=0.9808$

(7)

5. $\ln y=a+b x+c x^{2}+d x^{3}+e x^{4}$

Correlation coefficient $r^{2}=0.9808$

The following 80 equations keep $r^{2}>0,9$ significant, the simplest being:

46. $y=a+b x$

Correlation coefficient $\mathrm{r}^{2}=0.9801$

60. $y^{2}=a+b x$

Correlation coefficient $\mathrm{r}^{2}=0.9774$

86. $\ln y=a+b x^{2}+c e-{ }^{x}$

Correlation coefficient $r^{2}=0.9017$

The latest equations move suddenly from a correlation coefficient close to a credible 0.8 to one below 0.2 which does not show a linear behaviour of the response to strains. These are:

115. $\mathbf{y}=\mathbf{a}+\mathbf{b x}^{3}, \mathrm{r}^{2}=0.7827$,

116. $\mathbf{y}^{2}=\mathbf{a}+\mathbf{b x}^{3}, \mathbf{r}^{2}=0.7462$,

118. $\mathbf{y}=\mathbf{a}+\mathbf{b} /\left(\mathbf{1}+((\mathbf{x}-\mathbf{c}) / \mathbf{d})^{2}\right), \mathrm{r}^{2}=0.1391$,

The coefficients for the first equation are: $\mathrm{a}=2.199971541$; $\mathrm{b}=-0.04744094 ; \mathrm{c}=-0.00034074 ; \mathrm{d}=3.31795 \mathrm{e}^{-5}$; $\mathrm{e}=-5.3302 \mathrm{e}^{-}$

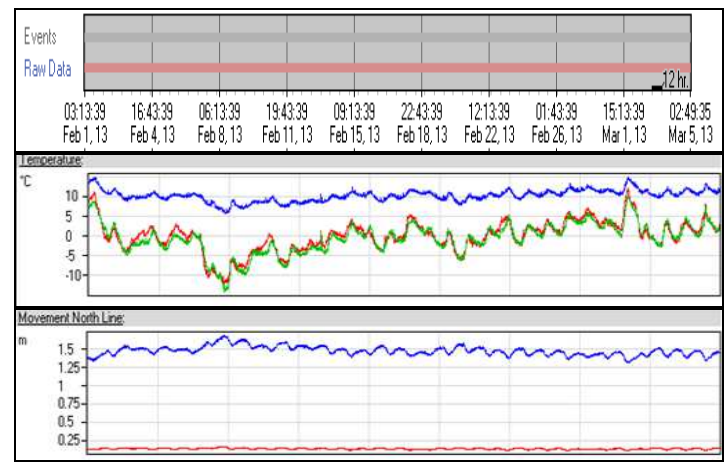

a.

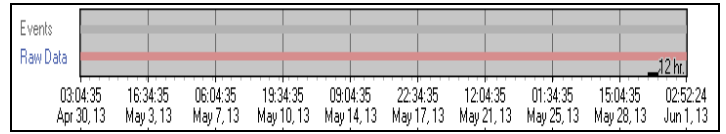

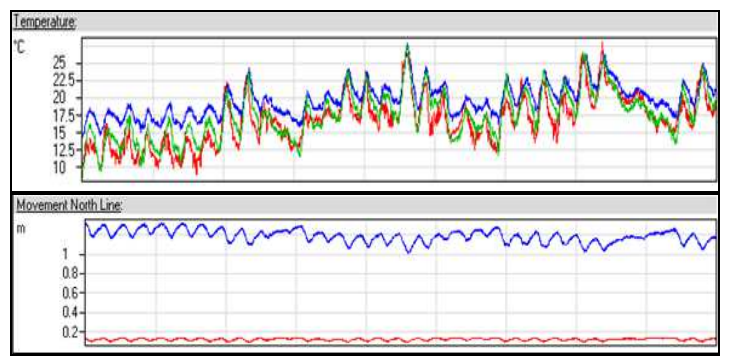

b.
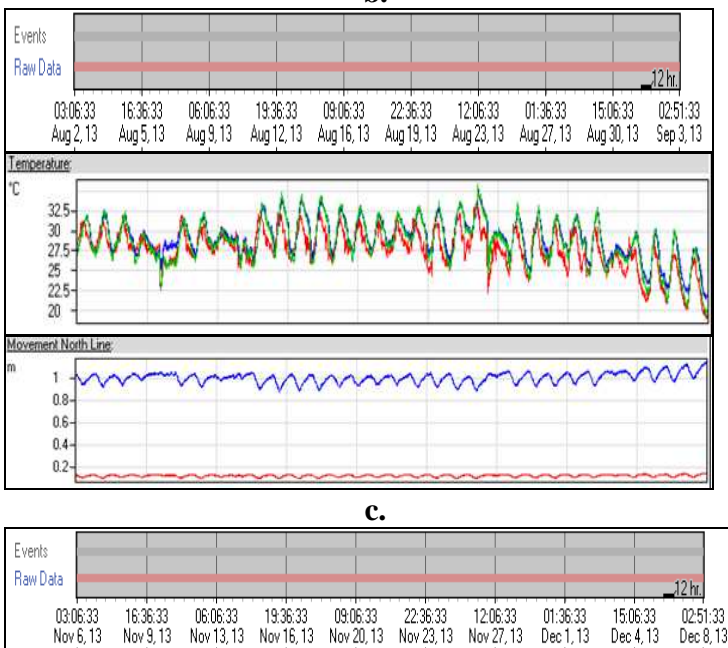

Tencelatur
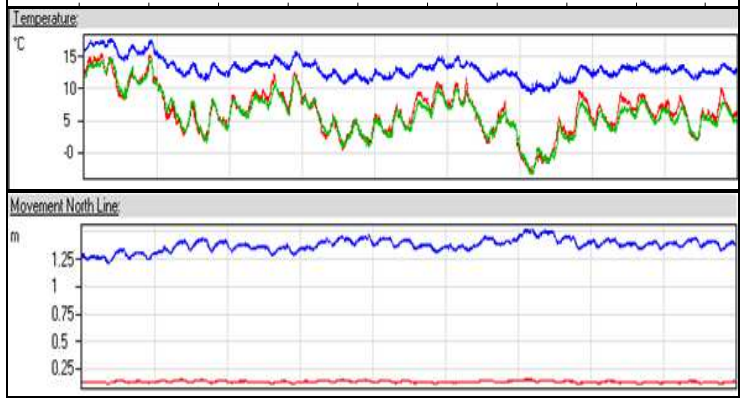

d.

Figure 2. Temperature evolution and movement of s north line elements, in the interval a. 01.02.2013, 03.13.39. 05.03.2013, 02.49.35; b. 30.04.2013, 03.04.35. 01.03.2013, 02.49.35; c. 02.08.2013, 03.06.33. 03.09.2013, 02.51.33; d. 06.11.2013, 03.06.33. 08.12.2013, 02.51.33; with each 15 minutes recording (Source: VCE/Authors) 


\begin{tabular}{|c|c|c|c|c|c|c|c|c|c|}
\hline \multirow{3}{*}{\multicolumn{2}{|c|}{$\begin{array}{l}\text { Predictive values } \\
\text { given by the } \\
\text { mathem. model }\end{array}$}} & \multirow{3}{*}{\multicolumn{2}{|c|}{$\begin{array}{l}\text { Values measured } \\
\text { on the real model }\end{array}$}} & \multirow{3}{*}{$\begin{array}{l}\text { Dif. } \\
\text { R/M }\end{array}$} & 76. 25.45 & 1.046 & 25,45 & 1,079 & +33 \\
\hline & & & & & 77. 26.06 & 1.036 & 26,05 & 1,011 & -25 \\
\hline & & & & & 80.27 .87 & 1.004 & 27,87 & 1,030 & +26 \\
\hline \multirow{2}{*}{ Temp. ${ }^{\circ} \mathrm{C}$} & \multirow{2}{*}{$\begin{array}{c}\text { Val. } \\
\text { m }\end{array}$} & \multirow{2}{*}{ Temp. ${ }^{\circ} \mathrm{C}$} & \multirow{2}{*}{ Val.m } & \multirow{2}{*}{$\mathrm{mm}$} & 81. 28.48 & 0.994 & 28,47 & 1,021 & +27 \\
\hline & & & & & 82. 29.09 & 0.983 & 29,08 & 1,002 & +19 \\
\hline 1. -20.00 & 1.631 & - & - & - & 83. 29.69 & 0.972 & 29,68 & 1,027 & +55 \\
\hline 2. -19.39 & 1.635 & - & - & - & 84. 30.30 & 0.960 & 30,29 & 0,949 & -11 \\
\hline 3. -18.78 & 1.638 & - & - & - & 85.30 .90 & 0.949 & 30,90 & 0,948 & -1 \\
\hline 5. -17.57 & 1.642 & - & - & - & 86. 31.51 & 0.937 & 31,52 & 0,930 & -7 \\
\hline 6. -16.96 & 1.643 & - & - & - & 87. 32.12 & 0.925 & 32,13 & 0,956 & +31 \\
\hline 9. -15.15 & 1.642 & - & - & - & 90.33 .93 & 0.887 & 33,39 & 0,909 & +22 \\
\hline $10 .-14.54$ & 1.640 & - & - & - & 91. 34.54 & 0.873 & - & - & - \\
\hline 11. -13.93 & 1.638 & - & - & - & 92. 35.15 & 0.859 & - & - & - \\
\hline 14. -12.12 & 1.629 & - & - & - & 94. 36.36 & 0.829 & - & - & - \\
\hline 15. -11.51 & 1.625 & $-11,60$ & 1,673 & +48 & 96. 37.57 & 0.796 & - & - & - \\
\hline 16. -10.90 & 1.620 & $-10,80$ & 1,683 & +63 & 97. 38.18 & 0.778 & - & - & - \\
\hline
\end{tabular}

Table 2. Values of predicted and measured displacements and differences (Source: Authors by Table Curve 2D)

Analyzing the data in Table 2 we see that the differences between the measured values $(\mathrm{R})$ and the results obtained by applying the created mathematical model (M) is between $+63 \mathrm{~mm}$ and $-67 \mathrm{~mm}$. Note that the measured values were extracted from the original unfiltered field data table, which justifies the great differences mentioned above. Moreover, the table on residual values, of which we present the top ten values, lists these differences that do not exceed $\pm 4 \%$, which certifies the quality of the Rank 1 mathematical model presented in Figures 3 and 4.

\begin{tabular}{|c|c|c|c|c|c|}
\hline \multicolumn{6}{|c|}{ 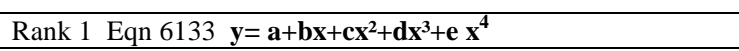 } \\
\hline & $X$ Value & Y Value & Y Predict & Residual & Residual $\%$ \\
\hline 1 & -11.60000 & 1.6730080 & 1.6257294 & 0.0472786 & 2.8259617 \\
\hline 2 & -11.40000 & 1.6707050 & 1.6243020 & 0.0464030 & 2.7774532 \\
\hline 3 & -11.10000 & 1.6766180 & 1.6220712 & 0.0545468 & 3.2533829 \\
\hline 4 & -11.00000 & 1.6920650 & 1.6213041 & 0.0707609 & 4.1819259 \\
\hline 5 & -10.80000 & 1.6831650 & 1.6197352 & 0.0634298 & 3.7684867 \\
\hline 6 & -10.70000 & 1.6314610 & 1.6189335 & 0.0125275 & 0.7678711 \\
\hline 7 & -10.60000 & 1.6060440 & 1.6181205 & -0.012076 & -0.751939 \\
\hline 8 & -10.50000 & 1.6716990 & 1.6172962 & 0.0544028 & 3.2543425 \\
\hline 9 & -10.30000 & 1.6040590 & 1.6156142 & -0.011555 & -0.720372 \\
\hline 10 & -10.00000 & 1.6115120 & 1.6130089 & 0 & -0.092887 \\
\hline
\end{tabular}

Table 3. Values of predicted and measured displacements given by the software, size and the percentage of residual values (Source: Authors by Table Curve 2D) (Source: Authors by Table Curve 2D) 


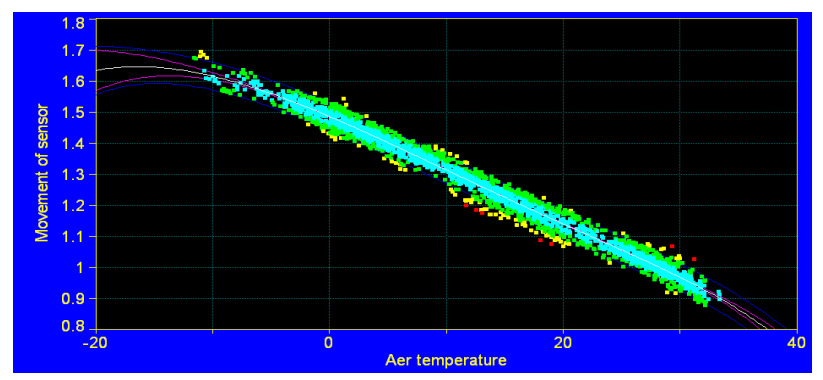

Figure 3. Distribution of measured data in relation to the curve defined by the Rank 1 equation (Plot Table Curve 2D)

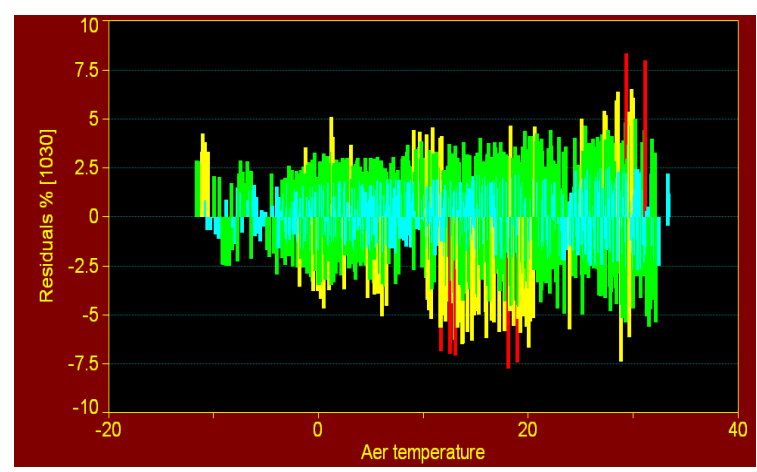

Figure 4. Distribution of residual values in relation to the regression line (Plot Table Curve 2D)

We then try to improve the quality of the mathematical model by a first iteration performed by entering data into the IBM SPSS 21 statistical software. A first finding is that the accuracy of the co-relation between data is very good, $98 \%$ respectively (Figure 5). Figures 6, 7 and 8 show other reports of the software selected to filter through successive iterations the data pairs (cause- air temperature and effectmovement of the sensor mounted on the element of Bridge Gap from North line.

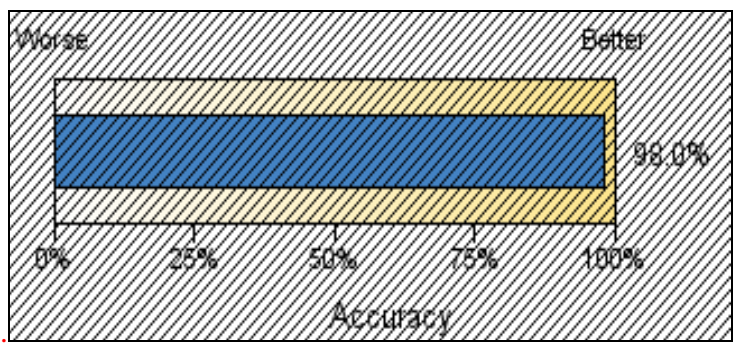

Figure 5. IBM SPSS 21 report on the accuracy of the corelation between data (Plot IBM SPSS 21)

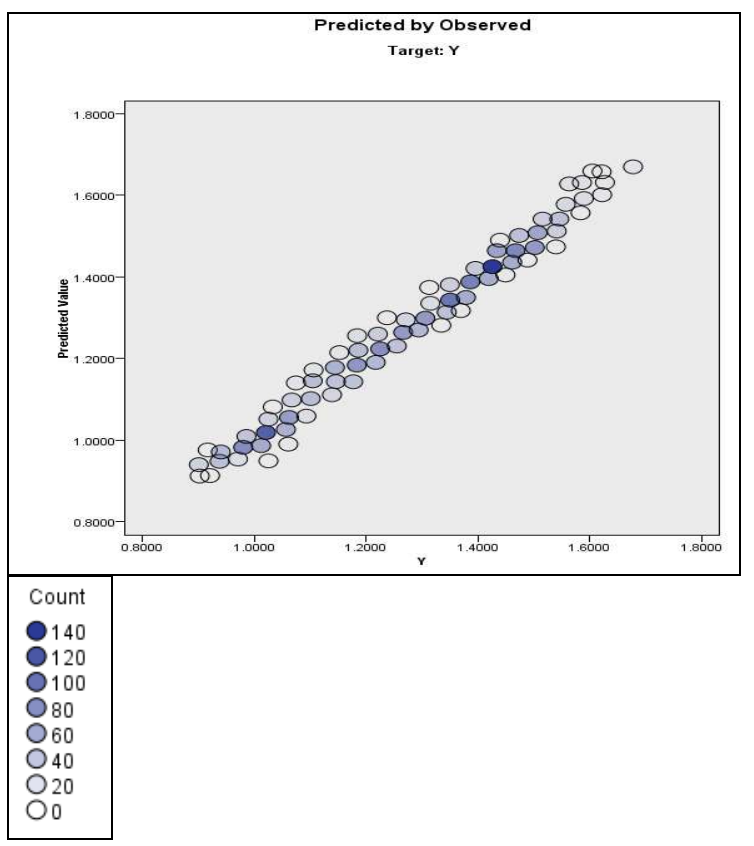

Figure 6. IBM SPSS 21 report on the relationship between prediction and observed -measured data (Plot IBM SPSS 21)

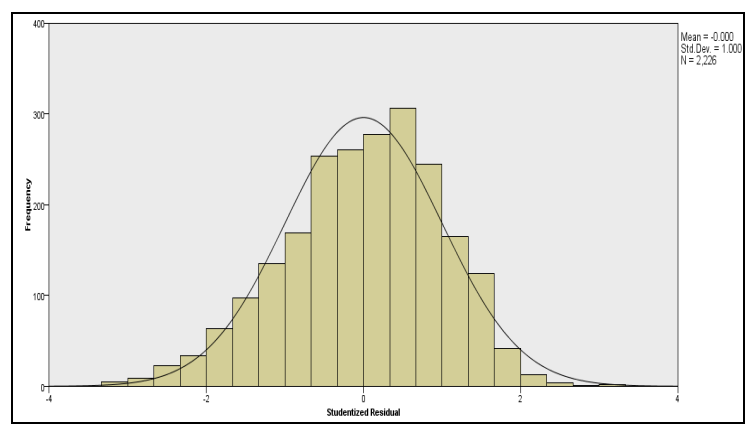

Figure 7. IBM SPSS 21 report on the percentage distribution of mutual sizes (Plot IBM SPSS 21) 


\begin{tabular}{|c|c|c|}
\hline Record ID & $r$ & Cook's Distance \\
\hline 17 & 1.5666 & 0.008 \\
\hline 19 & 1.5652 & 0.008 \\
\hline 2082 & 1.0668 & 0.008 \\
\hline 22 & 1.5616 & 0.007 \\
\hline 2186 & 1.0255 & 0.007 \\
\hline 24 & 1.5587 & 0.007 \\
\hline 18 & 1.5731 & 0.006 \\
\hline 23 & 1.5645 & 0.006 \\
\hline 20 & 1.5688 & 0.006 \\
\hline 7 & 1.6060 & 0.006 \\
\hline 2042 & 0.9188 & 0.005 \\
\hline 31 & 1.5533 & 0.005 \\
\hline 9 & 1.6041 & 0.005 \\
\hline 12 & 1.5959 & 0.005 \\
\hline
\end{tabular}

Figure 8. IBM SPSS 21 report on the list of deleted data pairs which we considered that are not relevant in the construction of the mathematical model of the relationship between data (Source: IBM SPSS 21)

\subsection{Data processing after the first selection, time} interval for recording - one hour

Following the IBM SPSS 21 report we see that we have to eliminate a total of 92 data pairs distributed like so:

Between $-11,6^{\circ} \mathrm{C}$ şi $\pm 0^{\circ} \mathrm{C}, 26$ data pairs; $28,2 \%$.

Between $\pm 0^{\circ} \mathrm{C}$ şi $+10^{\circ} \mathrm{C}, 9$ data pairs; $9,8 \%$.

Between $+10^{\circ} \mathrm{C}$ şi $+20^{\circ} \mathrm{C}, 12$ data pairs; $13,0 \%$.

Between $+20^{\circ} \mathrm{C}$ şi $+35^{\circ} \mathrm{C}, 45$ data pairs; $48,91 \%$.

It is found that almost half of the data removed are from the temperatures of over 20 degrees. Initial data in the Excel table on the measured data are filtered by removing pairs of data reported to be non-compliant by the software. After eliminating them the remaining pairs of data are returned to the mathematical model building software obtaining a better mathematical model. The Rank 1equation being:

$$
Y=a+b x+c x^{2}+d x^{3}+e-e-x
$$

It is noted that this equation takes the form of the Rank 4, equation (7) from the initial iteration, but it has a better correlation coefficient than the previous Rank 1 equation:

$\mathrm{r}^{2}=0.9846643655$, and the coefficients are: $\mathrm{a}=1.484351721 ; \mathrm{b}=-0.01624975 ; \mathrm{c}=-7.678 \mathrm{e}-05 ; \quad \mathrm{d}$ $=1.59853 \mathrm{e}-06 ; \quad \mathrm{e}=4.1022 \mathrm{e}-07$;

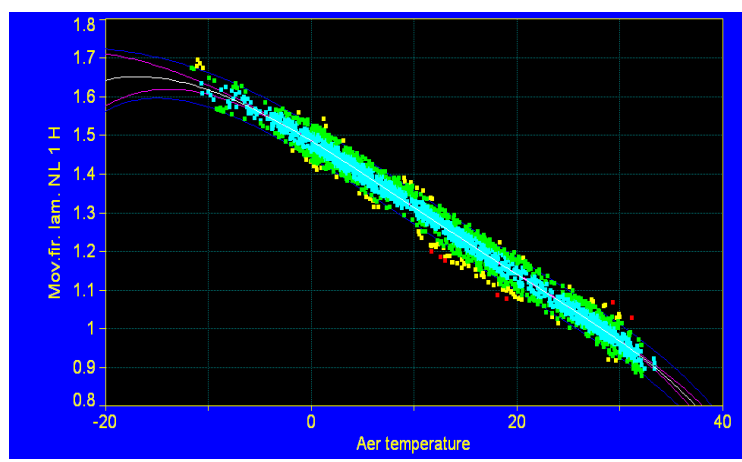

Figure 9. Distribution of measured data in relation to the curve defined by the Rank 1 equation, Input data after iteration no. 1 in IBM SPSS (Plot Table Curve 2D)

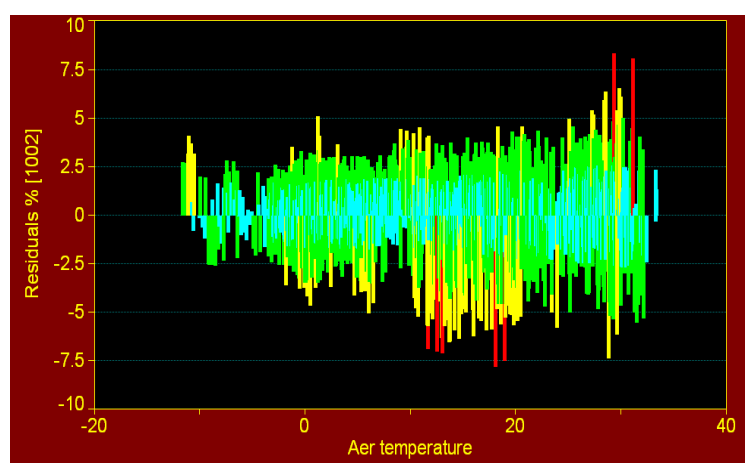

Figure 10. Distribution of residual values in relation to the regression line, Input data after iteration no. 1 in IBM SPSS (Plot Table Curve 2D)

\subsection{Validation of the mathematical model created after a first iteration}

In Table 4 the authors validate the last mathematical model showing, from one degree to the next, the measured and predictable values, the residual size and its percentage. There is a significant decrease in the size of residual values, and the percentage. 


\begin{tabular}{|c|c|c|c|r|r|}
\hline Nr. & $\begin{array}{c}\mathrm{X} \\
\text { Valu } \\
\mathrm{e}\end{array}$ & $\begin{array}{c}\text { Y } \\
\text { Value }\end{array}$ & Y Predict & $\begin{array}{c}\text { Residua } \\
1\end{array}$ & $\begin{array}{c}\text { Residual } \\
\%\end{array}$ \\
\hline 1 & -11.60 & 1.673 & 1.696 & -0.023 & -1.39 \\
\hline 6 & -10.50 & 1.671 & 1.651 & 0.020 & 1.22 \\
\hline 8 & -9.42 & 1.640 & 1.626 & 0.013 & 0.80 \\
\hline 11 & -8.27 & 1.622 & 1.607 & 0.015 & 0.93 \\
\hline 17 & -7.31 & 1.604 & 1.593 & 0.010 & 0.67 \\
\hline 18 & -7.25 & 1.571 & 1.592 & -0.021 & -1.36 \\
\hline 33 & -6.00 & 1.584 & 1.574 & 0.010 & 0.67 \\
\hline 46 & -5.01 & 1.559 & 1.559 & 0.000 & 0.01 \\
\hline 53 & -3.99 & 1.566 & 1.544 & 0.021 & 1.39 \\
\hline 93 & -3.00 & 1.520 & 1.529 & -0.009 & -0.60 \\
\hline 130 & -2.02 & 1514 & 1.489 & -0.024 & -1.65 \\
\hline 18 & -1.01 & 1498 & 1.469 & -0.028 & -1.96 \\
\hline 233 & 0.02 & 1.431 & 1.482 & -0.050 & -3.51 \\
\hline 322 & 1.01 & 1.413 & 1.466 & -0.053 & -3.76 \\
\hline 407 & 2.01 & 1.452 & 1.450 & 0.002 & 0.19 \\
\hline 499 & 3.03 & 1.409 & 1.433 & -0.023 & -1.65 \\
\hline 585 & 4.00 & 1.408 & 1.417 & -0.008 & -0.59 \\
\hline 684 & 5.00 & 1.412 & 1.400 & 0.012 & 0.89 \\
\hline 741 & 6.00 & 1.364 & 1.383 & -0.019 & -1.39 \\
\hline 790 & 7.00 & 1.397 & 1.366 & 0.0310 & 2.22 \\
\hline 849 & 8.03 & 1.346 & 1.348 & -0.001 & -0.140 \\
\hline 920 & 9.00 & 1.350 & 1.331 & 0.018 & 1.39 \\
\hline 966 & 10.00 & 1.325 & 1.314 & 0.011 & 0.83 \\
\hline 1018 & 11.00 & 1.308 & 1.297 & 0.011 & 0.88 \\
\hline 1080 & 12.01 & 1.280 & 1.279 & 0.001 & 0.12 \\
\hline 1137 & 13.02 & 1.264 & 1.261 & 0.002 & 0.22 \\
\hline 1192 & 14.00 & 1.276 & 1.244 & 0.032 & 2.52 \\
\hline 1250 & 15.00 & 1.215 & 1.226 & -0.011 & -0.91 \\
\hline 1311 & 16.00 & 1.200 & 1.209 & -0.008 & -0.69 \\
\hline 1375 & 17.00 & 1.174 & 1.191 & -0.017 & -1.48 \\
\hline 1445 & 18.00 & 1.201 & 1.174 & 0.027 & 2.32 \\
\hline 1501 & 19.03 & 1.096 & 1.155 & -0.059 & -5.40 \\
\hline 1544 & 20.01 & 1.140 & 1.138 & 0.001 & 0.15 \\
\hline 1585 & 21.05 & 1.164 & 1.120 & 0.043 & 3.75 \\
\hline 1621 & 22.01 & 1.104 & 1.104 & 0.000 & 0.03 \\
\hline & & & & & \\
\hline 19 & & & \\
\hline
\end{tabular}

Table 4. Validation of the mathematical created model It presents the calculation of the approximation accuracy of the mathematical model created on the correlation between aer temperature and sensor position on the Bridge Gap from North line, for significant temperatures (Source: Table Curve 2D)

\section{CONCLUSIONS}

Mathematical modelling complements the structural monitoring activity, adding extra meaning and significance to the data obtained by direct or indirect measurement.

There is a number of software operating with different amounts of datasets, from 2000 to a virtually unlimited number. Data can be passed through several software in order to obtain a mathematical model. The case presented is one in which, from the very the beginning, by introducing the data measured in the mathematical modelling, without selection and sorting thereof, only by one-quarter data reduction by halving, we can create a mathematical model with a correlation coefficient above 0.9 . However, the authors conducted another iteration just to show that through successive iterations, passing data through several software, each with a role of sorting and elimination of data considered insignificant, others meant to construct a credible mathematical model, we can obtain good results of the modelling process. Obviously, the famous linear regression equation $y=a+b x$, represented graphically by a straight line (Figure 11) can often mathematically represent the cause-effect ratio. This is the case of equation (9) with a correlation coefficient $r^{2}=$ 0.9801 . Nevertheless, the construction of the mathematical model should be stopped after a certain iteration, before it turns into the straight line shown in the last figure. The answer to this challenge depends on several criteria. The perception of specialists is that from that point on the model starts devolving and may no longer represent the actual process.

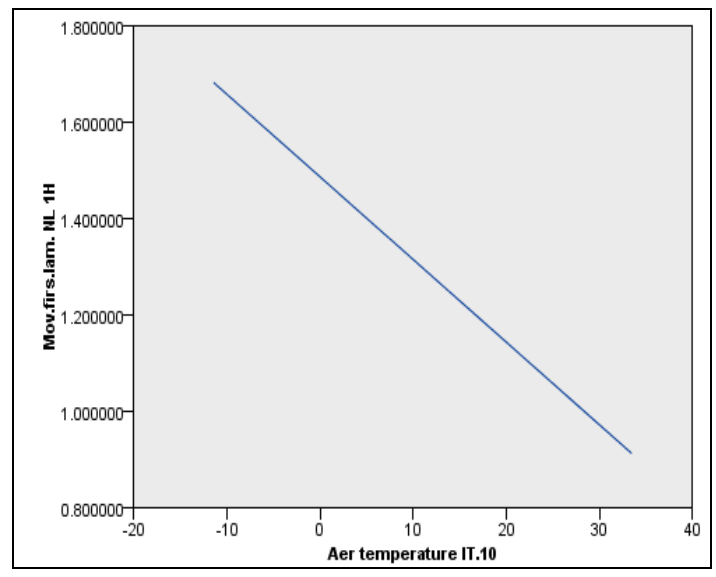

Figure 11. Estimated means or the top significant effects (Source: Plot IBM SPSS 21) 


\section{ACKNOWLEDGEMENTS}

Special thanks to the Vienna Consulting Engineers ,from Austria for providing the real-time data and for a very good collaboration with us ,initiated in 2009. Known as one of the most important companies carrying out structural monitoring work, led by Professor Helmut Wenzel, the company has made over 6000 projects in over 60 countries.

\section{REFERENCES}

Brent M. et all., 2005, Health Monitoring of Bridge Structures and Components Using Smart Structure Technology, Volume 2, Center for Transportation Research and Education Iowa State University January 2005.

Draper R., Smith H., 1998, Applied Regression Analysis, Wiley series in probability and statistics, Texts and references section.

Eric E., 1993, The Database Monitoring System: Making It Work. Comprehensive Regional Centers for Minorities Proceedings of the Eastern (Baltimore, Maryland, October 2-3, 1993) and Western (El Paso, Texas, October 9-10, 1993) Regional Conferences.

Gikas, V. and Sakellariou, M.,2008, Settlement analysis of the Mornos earth dam Evidence from Numerical Modeling and Geodetic Monitoring, Engineering Structures. 2008; 30(11):3074-3081.

Lane D., 2012, Introduction to Linear Regression, Online Statistics Education: An Interactive Multimedia Course of Study Developed by Rice University (Lead Developer), University of Houston Clear Lake, and Tufts University

Lovejoy S., 2010, Applications of structural health monitoring to highway bridges, http://www.oregon.gov/ODOT/HWY/

BRIDGE/docs/SHM_SCL_submission.pdf

Mosteller F., Tukey JW, 1977, Data analysis and regression: a second course in statistics, Addison-Wesley Series in Behavioral Science: Quantitative Methods. XVII, $588 \mathrm{p}$.

Nau R. 2015, Statistical forecasting: notes on regression and time series analysis, Notes and materials for an advanced elective course on statistical forecasting that is taught at the Fuqua School of Business, Duke University.

Rădulescu G.M.T., 2015, Theoretical and experimental research on structural geometric monitoring of constructions through surveying and alternative methods, Habilitation Thesis, Technical University of Cluj Napoca.

Radulescu A.T.G., 2013, Structural Monitoring Today, Modern Surveying Technologies used to Track Behavior over Time of Buildings, Lap Lambert Academic Publishing.

Sikorsky C., 1999, Identification of gaps in structural health monitoring technologies for bridges, https://www.pwri.go.jp/ eng/ujnr/tc/g/pdf/22/22-113sikorsky.pdf.

VCE-Vienna Consulting Engineers, 2009-2015, Permanent Structural Health Monitoring Systems, available at: http://www.brimos.com/DMA/ DMA Frames.

http://www.vce.at/, accesed 2009-2015.

http://www.sigmaplot.com/products/tablecurve2d/tablecur ve2d.php.

http://www-01.ibm.com/software/ro/analytics/spss/.

http://www.incheonbridge.com/, accesed 2009-2015. 
